drew off about one ounce and a half of urine, which was pale and clear, and on examination afterwards found it contained a considerable quantity of blood-colouring matter, with a very few hyaline casts and a large quantity of spheroidal epithelial cells like renal epithelium; sp. gr. 1020 ; albumen one-eighth. The bowels had not been open since I left in the morning. I gave her another drachm of the compound jalap powder, and kept her on the diluents and diuretic mixture, with the same light diet; hot fomentations to her loins as before. The milk had appeared in the breasts now.

30th.-It was now the fifth day after her confinement, and during that time the urine drawn off and passed was about two ounces. Her bowels had acted twice. This morning I found her weaker, and she had passed a very restless night. Her breathing was not at all impaired, and the heart worked fairly well. Temperature $99^{\circ}$; pulse 86. Tongue covered with the same yellow fur, but not quite so much. She had romited once since the evening before. Lochia continued. Her appetite was very bad, and her mother found it difficult to get her to take anything. I proposed a consultation with another medical man, to which the relatives agreed. Accordingly at 6 P.M. I went with Dr. S- - , and found that the patient had had an action of the bowels, once freely, since my last visit, but she had voided no urine, nor could we on percussion make out any in the bladder. She talked more cheerily than usual tonight, and seemed in better spirits; otherwise there was not the slightest change in her. Pulse 86 ; temperature $991^{\circ}$ tongue still covered with yellow fur. The same treatment was pursued, and we left about 7 P.M. At 9 P.M. I was called again to see her by her father, who told me that he though his daughter had fainted. I thought perhaps she was comatose, so I took some pilocarpine with me, but on my arrival 1 found her dead. Her mother said that since we left the house she had appeared quite cheerful, that she had passed about a wineglassful of urine, and that her bowels had acted. She asked her mother to hold her in her arms, and it was while in this position that she turned on one side and died almost instantaneously. There was no convulsion of any sort. This is all I could get from the mother.

The appearance post mortem presented nothing very extraordinary. I could not obtain a necropsy, which I should much like to have done. I should be much obliged for any suggestions as to the pathology \&c. of this as a complication of parturition. Ought any very prompt measures to have been taken at the onset of the disease, although so few symptoms presented themselves?

Widecombe, Devon.

\section{Clinical allote:}

MEDICAL, SURGICAL, OBSTETRICAL, AND THERAPEUTICAL.

\section{A CASE OF CONGENITAL DISLOCATION OF RADIUS.}

$$
\text { BY R. HeELIS, M.B. }
$$

J. H- aged eight years, was brought to me by his mother, and I was asked to look at his left arm. At first the only abnormality I noticed was a swelling on the outer and anterior part of the forearm just below the elbow; but on a slight movement of the arm the head of the radius slipped out of place, and I was led to examine the case more closely, with the following result: The left radius is generally in its dislocated position, and if reduced any slight motion will throw it out of place again, especially pronation. In complete flexion the dislocation is reduced; it can easily be reduced by manipulation in any position of the forearm, as the joint is so loose and there is some lateral movement possible in the humero-ulnar articulation. The right radius is partially dislocated--that is to say, only about one-fifth of the circumference of the head rotates on the external condyle of the humerus, the rest projecting behind and to the outer side of the joint. This dislocation is irreducible-at any rate, unless considerable force were employed. The external humeral condyles on both sides appear to be unusually small, hence the difficulty of retaining the dislocated bone on the left side in position. The dislocation therefore is similar on both sides, being outward and backward. When the arms are extended there is a considerable projection on the outer and upper part of both forearms, produced partly by the outward dislocation and partly by the disproportionate development of the supinator longus. All the normal movements can be performed by both forearms, but pronation and supination, especially the latter are very weak, and their place is usually taken by movements of flexion and extension. The patient seldom uses his right arm, which is less muscular than the left. The existence of some deformity has been noticed by the parents since his first year, and even from birth. There is no history of any accident to the boy or to the mother during gestation, or at delivery, which was normal. The boy is fairly well developed; his incisor teeth are very irregular, the two upper lateral or central ones being absent. He is loosejointed. His manner is very restless, and has been since an attack of chorea three years ago, which chiefly affected his left arm and lasted one year. He is very backward in his education, scarcely knowing his alphabet. The patient's mother is healthy, and has had no miscarriages. The father is of strumous appearance and subject to styes. The brother, the only other child, has interstitial keratitis.

Remarks.-I believe the dislocations to be congenital, because they are symmetrical, and because they have been noticed almost since birth, and there is no history of accident to account for their appearance. The defective development of the teeth, bones, and joints, the backward intellect, and the attack of chorea seem to support the theory which refers congenital dislocations to lesions of the central nervous system. Nottingham.

\section{A CASE OF}

PARAMETRIC PHLEGMON FOLLOWING HYDATIDIFORM MOLE.

By G. HenRY Browne,

SURGEON, WAENAYON AND OLYDACH-MERTHYR COLLERIES,

Mrs. $X-$, aged thirty-two, a thin, pale woman, multipara, ceased menstruating on June 24th. Six weeks from this date flooding set in without assignable cause, which was checked by ergot and opium. A month later still the hæmorrhage recurred, and was again checked by the usual remedies. The patient had no further trouble till Oct. 4th, when an urgent message came for me to see her about 1 A.M. that morning. On arrival I found her suffering from very profuse hæmorrhage, the abdomen presenting the size of a seven months' pregnancy, but doughy on palpation, while per vaginam the os, soft and dilatable, was expanded to the size of a florin. From this condition of the parts I diagnosed hydatidiform mole, which diagnosis was subsequently confirmed by a portion coming away having the characteristic white-grape appearance. Ergot was given and a Barnes bag used to avert hæmorrhage and dilate, severe pains almost immediately coming on. In about twenty minutes I removed the bag, when an enormous quantity of the cysts, nearly amounting to six pints, was expelled. The hæmorrhage at this time was extreme, and ergot was again resorted to with brandy, while with my left hand I grasped the uterus, which alternately contracted and relaxed, and with my right passed a few grains of iron-alum up to the os; immediate contraction then ensued and no further hæmorrhage occurred. From the great loss of blood the patient sank to the lowest ebb, being at one time almost pulseless, but rallied under the use of stimulants. When seen again at 11 A.M. her state was somewhat improved, pulse stronger, and temperature normal, and she was then ordered teaspoonful doses every hour of essence of beef (Lion brand) with a mixture containing ten minims of solution of extract of ergot, ammonia, and bark every four hours. Nothing untoward happened until eight days later on, when the patient was seized with a rigor soon after my morning visit, the lochia ceasing and the temperature rising to $101^{\circ}$, with a pulse of 101 . She now complained for the first time of severe pain in the right groin, and on examination I found a large tumour, hard, inelastic, and dull to percussion, filling the whole of the right iliac fossa. I enjoined absolute rest in bed, treated the tumour locally with poultices and a liniment of iodide of potassium, belladonna, and glycerine, and gare her ten grains of quinine imme- 